\title{
Molecular Mechanisms of Depression: Perspectives on New Treatment Strategies
}

\author{
Undine E. Lang Stefan Borgwardt \\ University Hospital of Basel, Department of Psychiatry and Psychotherapy, Basel
}

\section{Key Words}

Depression • BDNF • Cardiovascular • Metabolic • Stress • Inflammation • Sleep • Glutamate

\begin{abstract}
Depression is a multicausal disorder and has been associated with the risk to develop cancer, dementia, diabetes, epilepsy and stroke. As a metabolic disorder depression has been associated with obesity, diabetes, insulin sensitivity, neuropeptide $Y$, glucose regulation, poor glycemic control, glucagone-like peptide-1, cholezystokinin, ghrelin, leptin, the endocannabinoid system, insulin-like growth factor and gastrin-releasing peptide. As a cardiovascular disease a close relationship exists between depression and blood pressure, heart rate, norepinephrine, sympathetic tone, vascular resistance, blood viscosity, plasma volume, intima thickness and atherosclerosis. Additionally blood coagulation, fibrinolysis, D-dimers, plasminogen activator inhibitor-1 protein, platelet activation, VEGF, plasma nitric oxide and its synthase are changed in depressed patients. As an endocrinological and stress disorder depression has been connected with the concentration of free $\mathrm{T}_{4^{\prime}}, \mathrm{TSH}, \mathrm{CRH}$, arginine vasopressin, corticotrophin, corticosteroid release and ACTH. Depression as an inflammatory disorder is mediated by pro-inflammatory cytokines, interleukin-1, interleukin-6, TNF-alpha, soluble interleukin-2 receptors, interferon-alpha, interleukin 8 , interleukin-10, hs-CRP, acute phase proteins, haptoglobin, toll like receptor 4, interleukin-1beta, mammalian target of rapamycin pathway, substance $\mathrm{P}$, cyclooxygenase-2, prostaglandin-E2, lipid peroxidation levels and acid sphingomyelinase. Nutritional factors might influence depression risk, i.e. the consumption of folate, omega-3 fatty acids, monounsaturated fatty acids, olive oil, fish, fruits, vegetables, nuts, legumes, vitamin B6 and vitamin B12. The neurodegenerative hypothesis of depression explains decreased hippocampal volumes in depressed patients and changes of neurotrophic support by BDNF, erythropoietin, GDNF, FGF-2, NT3, NGF and growth hormone. In this context, a fast neuroprotective and antidepressant effect has also been observed by ketamine, which acts via the glutamatergic system. Hence, GABA, AMPA, EAAT, NMDA- and metabotropic glutamate receptors (mGluR1 to mGluR8) have gained interest in depression recently. Alternative, causative or also easy available treatment strategies beyond serotonin and noradrenaline reuptake inhibition might be a major topic of future psychiatric care. In this review, an attempt is made to overview concepts of the disease and search for perspectives on antidepressant treatment strategies beyond approved medications.
\end{abstract}

Copyright $\odot 2013$ S. Karger AG, Basel

Prof. Undine Lang

Universitäre Psychiatrische Kliniken

Wilhelm Klein Str 27, 4056 Basel (Switzerland)

Tel. +41-61-325-5202, Fax +41-61-325-5518, E-Mail undine.lang@upkbs.ch 


\section{Introduction}

Depression is a common disorder, which occurs in all genders, ages, in all social backgrounds and also in animals. According to the World Health Organization, depression is the leading cause of disability as measured by disability adjusted live years and the $4^{\text {th }}$ leading contributor to the global burden of disease in 2000, with tendency to rise up to 2020 .

It presents with depressed mood, loss of interest, loss of drive and pleasure, feelings of guilt, poor concentration, low self-esteem, sleep disturbances and increased or decreased appetite. These problems can become chronic or recurrent and lead to substantial impairments in an individual's ability to take care of his or her everyday responsibilities. At its worst, depression can lead to suicide, a tragic fatality associated with the loss of about 850.000 lives every year.

Depression is a multifaceted disorder with diverse causes and has been associated with the risk to develop severe medical disorders, i.e. depression increases the risk for cardiovascular disorders by 1.5-2 fold [1], for stroke by 1.8 fold [2], for Alzheimers Disease by 2.1 fold [3], for epilepsy by 4-6 fold [4], for diabetes by $60 \%$ [5], for cancer by 1.3-1.8 fold [6] (Fig. 1).

Conventional treatment of depression with antidepressant medications and cognitive behavioral therapy can be effective in $60-80 \%$ of patients. However, fewer than $25 \%$ of those affected have access to effective treatment. Moreover, treatment resistant depression occurs in up to $40 \%$ of patients. However, antidepressant therapy has a variety of undesirable side effects such as sedation, decrease of blood pressure, increase of weight, indigestion or sexual dysfunction. This often results in patients' poor compliance resulting in a break-up of medication with recurrence of depressive symptoms and increased suicidal risk [7].

Therefore, (1) the prevention of depressive episodes by focusing on different possible physiologically relevant mechanisms beyond the neurotransmitter hypothesis and (2) the treatment of depression with alternative, causative or also easy available treatment strategies beyond serotonin and noradrenaline reuptake inhibition might be a major topic of future psychiatric care.

In this review, an attempt is made to overview new molecular concepts of the disease and search for perspectives on antidepressant treatment strategies beyond approved medications.

\section{Depression as a metabolic disorder}

The prediction is that in the US, one in three children will go on to develop Type 2 diabetes during her/his lifetime [8]. Research on health outcomes associated with obesity and diabetes has traditionally focussed on cardiovascular disease. However, metabolic dysregulation influences brain function and disturbances in peripheral glucose regulation might be associated with cognitive impairment and depressed mood [8]. Depression is highly associated with obesity, metabolic syndrome and type- 2 diabetes $[9,10]$ and it has even been discussed to classify depression as metabolic syndrome type II [11]. The presence of depressive symptoms is documented in $12.8-29 \%$ of males and $23.8-30.5 \%$ of females with newly diagnosed diabetes. Diabetes has in turn been shown to affect the incidence of depression [12] and depressive symptoms are predictive of poor glycemic control in type 2 diabetes mellitus patients [13]. Vice versa depression increases the risk for diabetes by $60 \%$ [5]. Cross-sectional data from a population-based cohort study of 2667 residents, show depressive symptoms to be indeed associated with glucose metabolism [10].

Nutrient activated gut to brain signaling pathways play a major role in the control of digestive function, appetite and energy intake. These include the modulation of gastric emptying and gastrointestinal transit and are regulated by the release of a number of signaling peptides from nutrient sensing enteroendocrine cells, glucagone-like peptide- 1 and cholezystokinin [14]. Also ghrelin, leptin and the lipid endocannabinoid system have been 


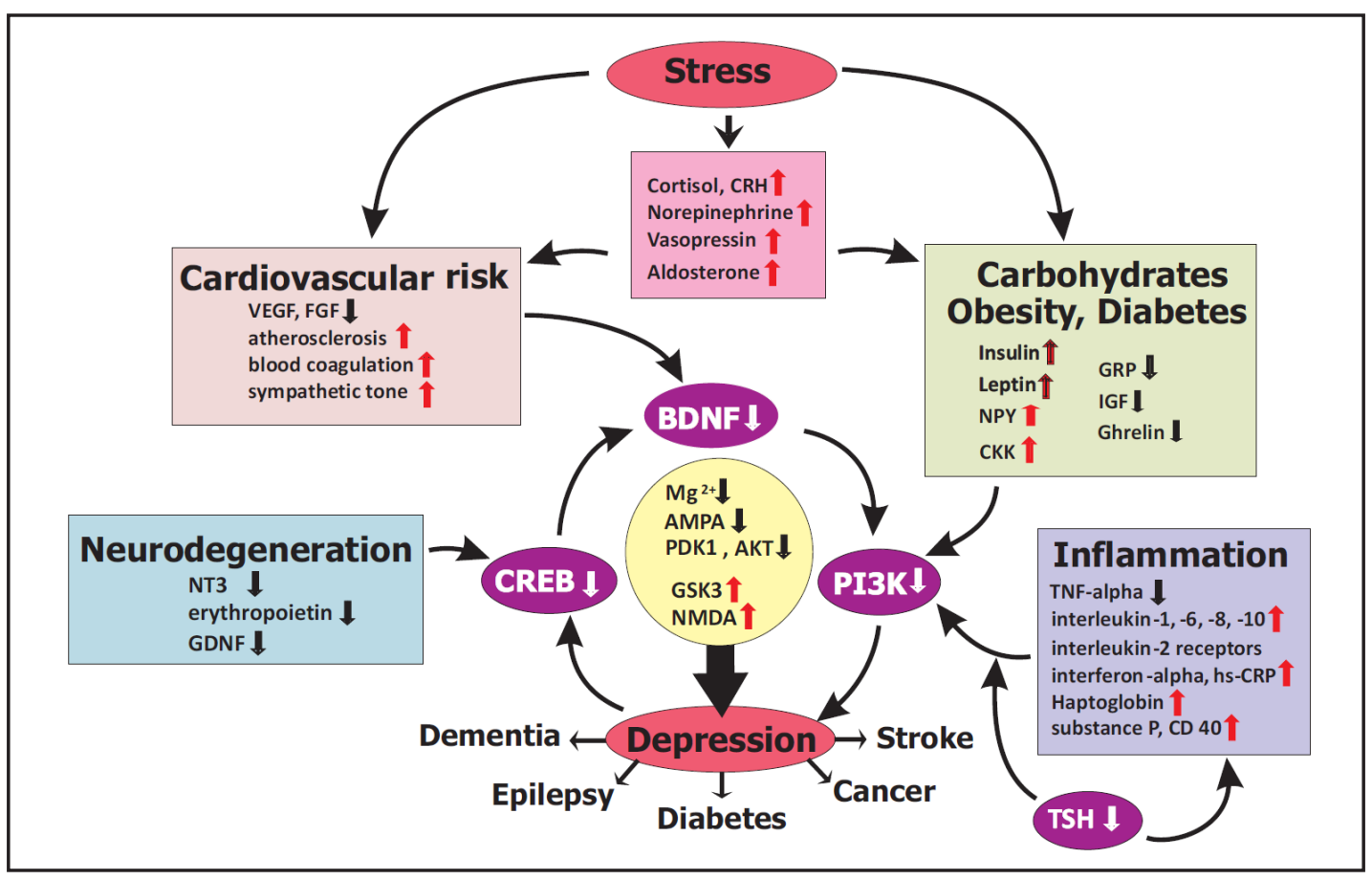

Fig. 1. Mechanisms leading to and resulting from depressive disorder.

shown to signal from the gut to the brain. Interestingly, all these gastrointestinal hormones gain interest in the regulation of mood and the treatment of depressive symptoms.

A highly significant association between leptin levels, depressed mood and sleep disturbances has been shown in normal-weight women [15]. Leptin is involved in hippocampal plasticity as the functional isoform of the leptin receptor and the glucocorticoid receptor are colocalized in hippocampal neural progenitor cells [16].Both, dexamethasone and leptin seem to converge on glycogen synthase kinase-3beta (GSK-3 $\beta$ ) and $\beta$-catenin [16] which are key regulators in controlling hippocampal neural progenitor cell proliferation [16]. Leptin can decrease the basal secretion of dopamine as well as feeding-stimulated dopamine release within the ventral striatum of rats [17]. Furthermore, leptin receptor activation inhibits firing of VTA dopamine neurons [18], whereas long-term blockade of leptin signaling in the VTA increases locomotor activity and food intake $[19,20]$.

Obesity and major depression may derive, moreover, from dysregulation of ghrelin feedback at brain regions regulating feeding and mood. Ghrelin regulates central system development and mood, exerts antidepressant effects in mice and men, influences the reward behaviour [21,22] and displays dopaminergic properties [23]. Carbohydrates appear to be the most effective macronutrients for ghrelin suppression [24]. Antidepressant effects were reported following ghrelin administration in mice and men [21, 22]. Interestingly, chronic stress, such as repeated social defeat, can elevate ghrelin levels by activation of the sympathetic nervous system and the increased ghrelin response then helps the subject cope with the stress by generating anxiolytic- and antidepressant-like behavioral adaptations [20].

Some cases of depression might result from dysfunction of the peripheral expression or the transport of insulin-like growth factor (IGF) into the brain. Also IGF increases hippocampal neurogenesis $[25,26]$ and a central sensitization of insulin signaling via IGF might reduce depressive symptoms [27]. IGF-1 regulates adult hippocampal neurogenesis [28], i.e. a blockade of peripheral IGF reduces exercise-induced neurogenesis [26]. Moreover, IGF produces antidepressant behavioural responses [29, 30]. 
Cholecystokinin is relevant to depressive-like symptoms and antidepressant therapy. Indeed, repeated social defeat triggers cortical cholecystokinin release and chronic antidepressant treatment prevents both depressive behaviour and the associated increase of cortical cholecystokinin release [31]. Blockade of cholecystokinin receptors reverses depressive behaviour in mice and prevents HPA axis hyperactivity [31]. Vice versa cholecystokinin injection leads to increased serum corticosterone. Panic induction can be experimentally carried out by a bolus injection of cholecystokinin [32] and decrease of cholecystokinin has been associated with mania, recently [33].

The mammalian bombesin-like peptide gastrin-releasing peptide (GRP) stimulates cell proliferation, displays a range of neuroendocrine activities, and acts as a growth factor in the pathogenesis of several types of human cancer [34]. GRP are distributed throughout the mammalian central nervous system. Pharmacological and genetic studies in rodents have shown that GRP in brain areas such as the hippocampus and amygdala are involved in regulating synaptic plasticity and aspects of anxious and depressive behaviour [34]. Behaviours modulated by the GRP in rodents include grooming, food intake, social behaviour and emotional-motivated learning and memory [34].

Chromium plays a crucial role in glucose and fat metabolism and improves insulin sensitivity in the hypothalamus, which enhances hypothalamic function by increasing glucose use, leading secondarily to an increased synthesis of serotonin, norepinephrine and melatonin $[35,36]$. Three pilot trials of chromium indicate an antidepressant effect in patients with unipolar depression when used as adjunctive or monotherapy [37-39].

Galanin is a regulatory 29-30-amino acid peptide, widely distributed in the nervous system and gut [40]. Galanin is synthesized in the 5-hydroxytryptamine (5-HT) neurons in the dorsal raphe nucleus and in the noradrenergic neurons in the locus coeruleus and is coexpressed with various neurotransmitters and neuropeptides in other types of neurons. Converging evidence implicates the regulatory neuropeptide galanin in anxiety- and depression-related behaviors, through modulation of neuroendocrine, serotonergic, and noradrenergic systems [41].

Neuropeptide Y was initially described as a 'co-transmitter' of sympathetic neurons, modulating the actions of norepinephrine in the cardiovascular system [42]. Later on, many other functions of Neuropeptide Y, in particular in the CNS were discovered, connecting Neuropeptide $\mathrm{Y}$ with the stress response, food intake, energy balance control, sleep regulation, inflammatory processes and tissue growth and remodeling [43]. Neuropeptide $\mathrm{Y}$ integrates complex responses of different body systems, such as reduction of anxiety and depression, inhibition of release of Neuropeptide Y, glutamate and GABA, angiogenesis and blood pressure regulation and regulation of circadian rhythms, bone formation and feeding response [44].

BDNF is a mediator of food intake control at brain areas rich in BDNF receptors, including the hypothalamus and it is moreover involved in vagal afferent gastrointestinal impulses and thereby drives overeating and weight gain associated with increased meal size and frequency. The deletion of BDNF in the brain led to a metabolic phenotype characterized by hyperphagia, obesity, and increased abdominal white adipose tissue [45]. Brain-derived neurotrophic factor (BDNF) has been involved in vulnerability to overeating and weight gain in an obesogenic environment.

\section{Depression as an endocrine disorder}

Corticotrophin-releasing hormone and arginine vasopressin are the central drivers of the stress hormone system, elicit corticotrophin into the periphery and thereby activate the corticosteroid release from the adrenal cortex. If these stress hormones are persistently hypersecreted they can also evoke severe clinical conditions and hamper an adequate adaptation to stress. These hormones also act as neuromodulators in the brain, affecting higher mental functions including emotion, cognition, and behaviour [46]. 
The core hypothesis of depression as a stress-related disorder is that chronic stresselicited corticosteroids impair corticosteroid-receptor signaling, which is a key risk factor in rendering an individual prone to stress-related disorders [46]. Indeed, glucocorticoidactivated glucocorticoid receptors are opposed by mineralocorticoid receptors which are rapidly activated and terminate humoral responses efficiently [47]. Results from open label and double-blind studies by several groups have indicated that corticosteroid synthesis inhibitors may be efficacious or of adjunctive value in some patients with depression, including those refractory to other agents; however, there is a need for more controlled studies [48].

The prevalence of depressive symptoms in hypothyroidism is near to $50 \%$ whereas in hyperthyroidism it reaches up to $28 \%$ of the cases $[49,50]$. Clinical depression occurs in more than $40 \%$ of people suffering from hypothyroidism [50, 51]. Indeed, low TSH levels in healthy individuals might be linked to an increased risk of depression [52]. Vice versa, patients suffering from depression display higher than expected rates of subclinical hypothyroidism.

The concentration of free $\mathrm{T}_{4}$ in the blood and cerebrospinal fluid is relatively increased during depression (at least in $30 \%$ of patients), being reduced when the clinical recovery occurs [50].

Therefore, the use of thyroid hormones to supplement antidepressants is based on evidence supporting a bidirectional connection between thyroid function and depression. Several randomized double-blind, placebo-controlled studies have shown an accelerated clinical response in patients, where a concomitant administration of thyroid hormone and antidepressant have been exerted [53]. Indeed, the augmentation of antidepressant treatment with triiodothyronine reaches the efficacy of the commonly used lithium augmentation [54]. In a recent review published by Nature, convincing evidence has been indicated that a role of type 1 iodothyronine deiodinase determines the serum T4:T3 ratio and a variant of phosphodiesterase determines TSH levels. Moreover, TSH-receptor variants, fasting glucose level, iodothyronine deiodinase variants and insulin-like growth factor production, hypertension and psychological well-being seem connected in their response to T3 or T4 treatment [55].

\section{Depression as a cardiovascular disease}

A close, bidirectional relationship exists between depression and cardiovascular disease [56]. Major depression is associated with an increased risk of coronary artery disease, myocardial infarction, congestive heart failure, and isolated systolic hypertension leading to increased mortality and morbidity in patients [56].

Blunted blood pressure reactivity, increased heart rate and altered autonomic baseline function have been observed in in dysphoric individuals. Elevation in systemic arterial pressure, higher circulating levels of norepinephrine, higher sympathetic tone, increased systemic vascular resistance, elevations in blood viscosity, decreased plasma volume and extracoronary atherosclerosis are associated with a higher prevalence of depressive disorders [57, 58]. Moreover, a strong relationship has been described between severe coronary and aortic calcifications, intima thickness, osteoporosis, and depressive disorders [58-62]. Additionally in depressed patients an increased blood coagulation and fibrinolysis, D-dimer, plasminogen activator inhibitor-1 protein and platelet activation can be observed $[63,64]$. Moreover, it was consistently shown that baseline levels of plasma nitric oxide, plasma nitric oxide metabolite, and platelet nitric oxide synthase activity were significantly lower in subjects with depression compared with that in healthy controls [65].

In conclusion, various pathophysiological mechanisms may underlie the risk of cardiovascular disease in patients with depression: increased inflammation, susceptibility to blood clotting, oxidative stress, hypothyroidism, hyperactivity of the sympathoadrenomedullary system and the hypothalamic-pituitary-adrenal axis, reductions in 
endothelial progenitor cells and arterial repair processes and decreased heart rate variability.

Statins have anti-inflammatory properties and accordingly, the use of statins was associated with significant reduction in the risk of depression in individuals who have had a cardiac event in a prospective clinical trial [66].

An acceleration and enhancement of the efficacy of antidepressant treatment has been associated with pindolol administered together with serotonine reuptake inhibitors, displaying a quicker and more pronounced decrease of symptoms in patients with nonresistant major depressive disorder [67].

Vascular endothelial growth factor (VEGF) is an endothelial cell mitogen and survival factor that regulates vascular function, but is also expressed in the brain and has neuroprotective and neurogenic effects [68-70]. Chronic stress exposure has been shown to decrease and antidepressant administration to increase hippocampal VEGF [71, 70]. Consistent with these results, it has been reported that VEGF expression and blood levels are increased in patients with depression and that antidepressant treatment reverses these effects $[72,73]$.

\section{Depression as an inflammatory disorder}

Clinical depression and sickness behaviour are occurring in response to nearly all physiological stressors and both are highly connected phenotypes. Sickness behaviour is characterized by malaise, hyperalgesia, pyrexia, disinterest in social interactions, lethargy, behavioural inhibition, reduction of locomotor activity, exploration and grooming, reduction of reproductive performance, anhedonia, somnolence and sleepiness, anorexia and weight loss, failure to concentrate and anxiety. This behaviour has been proved to be mediated by pro-inflammatory cytokines, such as interleukin-1, interleukin-6 and TNF-alpha [74]. Accordingly, depressive disorders could partly be based on inflammatory changes, i.e. increased interleukin-6, TNF-alpha, soluble interleukin-2 receptors, acute phase proteins, including C-reactive protein and haptoglobin $[75,76]$. In a recent meta-analysis of cytokines in major depression a total of 136 studies has been identified and in 24 included studies increased concentrations of the proinflammatory cytokines TNF-alpha and interleukin- 6 have been confirmed in depressed subjects when compared with healthy controls [76]. Moreover, toll like receptor 4, interleukin-1beta, cyclooxygenase-2, prostaglandin-E2 and lipid peroxidation levels are regulated by stress. These inflammatory cytokines can interact with virtually every pathophysiologic domain relevant to depression, including neurotransmitter metabolism, neuroendocrine function, and synaptic plasticity.

From an evolutionary point of view depressive and obsessive behaviour seem senseful in the context of an infection as social withdrawal and repetitive washing might save other individuals from contamination. Moreover, depression is a state, which might save energy and thereby help an individual to overcome severe infections. Indeed, there are rare cases, where depression and obsessive compulsive behaviour could causally be linked to streptococcal infections [77]. However, depressive patients, who are using nonsteroid anti-inflammatory agents, seem to respond poorly to -mainly serotonergicantidepressants [78]. In these conditions the inflammatory processes rather than the medication might lead to depressive behaviour $[78,79]$. Indeed, both pre-clinical and clinical studies have demonstrated that newer serotonin-noradrenalin antidepressants can inhibit the production and release of pro-inflammatory cytokines and stimulate the production of anti-inflammatory cytokines [80].Reductions in inflammation might therefore contribute to treatment response [80]. However, to our knowledge, an immunosuppressant effect of serotonergic antidepressants has not been studied systematically but might affect people with inflammatory diseases such as multiple sclerosis, cardiovascular disease, and psoriasis, who have elevated rates of depression. In this context tryptophan is an interesting example as tryptophan produces a consequent reduction in brain serotonin synthesis and release [81]. However, despite tryptophan's promising antimanic effects, the amino acid nutritional 
supplement has been banned by the food and drug administration since 1989 due to rare and deadly flu-like conditions associated with its use [82].

Vice versa, many people administered inflammatory cytokines such as interferonalpha develop depression that is indistinguishable from depression in non-medically ill populations [83]. Even completed suicides have been observed in response to treatment with interferon-alpha [83].

The importance of the inflammation hypothesis of depression lies in raising the possibility that psychotropic drugs that have a central anti-inflammatory action might provide a new generation of antidepressants. Both experimental and clinical evidence shows that a rise in glucocorticoids might lead to an increase of proinflammatory cytokines and these might in turn contribute to the behavioral changes associated with depression.

In this context, it has been suggested that the cyclooxygenase- 2 inhibitor celecoxib is a potential adjunctive treatment strategy for major depression [84, 85]. Moreover, the results of this study are in line with Nery et al. who have reported that celecoxib might produce a rapid-onset antidepressant effect in bipolar patients with depressive episodes [86]. In addition, the result of a recent study indicates that celecoxib treatment reverses chronic unpredictable stress-induced depressive-like behaviour [87].

In addition, the use of gram-negative antibiotics has been discussed to offer a potential therapeutic approach for the adjuvant treatment of depression [88]. Also Sesamol, which is a potent inhibitor of cytokine production as well as an antioxidant has been shown to reverse the unpredictable chronic stress-induced behavioral, biochemical, and inflammation surge in stressed mice, i.e. sesamol may have the potential to exert antidepressant effects [89].

\section{Depression as a matter of darkness}

Depression has been discussed as a matter of sunshine. In contrary, light deprivation has been shown to induce depression-like behaviour and suppresses neurogenesis [90]. Environmental light influences the secretion of melatonin. Melatonin is involved in a variety of diseases, including cancer, insomnia, depression, dementia, hypertension, and diabetes; its secretion is influenced by environmental light. Agomelatine is the first melatonin analogue antidepressant drug and has therefore led to a renewed focus on the potential clinical benefits that could be derived from modulation of the circadian system [91].

Daylight exposure increases not only nocturnal melatonin secretion but also platelet 5 -HT values [92] and vitamin D, which in turn has been involved in the pathophysiology of depression [93]. Season might be a possible confounding factor in reduced brain serotonin turnover following selective serotonin reuptake inhibitor therapy [94] and influences the cortisol response to awakening [95]. Serum BDNF concentrations also show strong seasonal variations and correlations with the amount of ambient sunlight [96]. However, also physical activity is higher on long days ( $\geq 14$ hours daylight) when compared with short days [97]. In conclusion, bright light treatment seems underused in the treatment of depressive disorders.

Bright light can stimulate the suprachiasmatic nucleus and therefore improve mood, sleep, and hormonal rhythms in patients with major depressive disorder. Bright light therapy improves mood, enhances sleep efficiency, and increases the melatonin level gradient. In addition to its chronobiotic effects, melatonin also increases sleep propensity, reduces sleep latency, decreases alertness and neurocognitive functioning, lowers core body-temperature, reduces adiposity, attenuates weight gain and has anti-oxidative effects [98]. Interestingly, melatonin administration inhibits insulin release, increases insulin sensitivity and adiponectin, leptin, and ghrelin plasma levels [99]. Melatonin also increases insulin sensitivity and glucose tolerance in animals fed with either high fat or high sucrose diet [100]. 
In a recent study, superior response and remission rates were obtained by chronotherapeutic strategy when compared with the effects of exercise in acute depressive patients treated with duloxetine [101]. Indeed, at week 9, response was obtained in $71.4 \%$ of wake therapy patients versus $47.3 \%$ of exercise patients and remission was obtained in $45.6 \%$ of wake therapy patients and $23.1 \%$ of exercise patients [101].

\section{Depression as a deficiency state}

Diet may potentially influence the risk of depression. In a recent meta-analysis several nutrient variables have been inversely associated with depression risk, i.e. the consumption of folate, omega-3 fatty acids, monounsaturated fatty acids, olive oil and fish and a diet rich in fruits, vegetables, nuts and legumes [102]. However, the exact mechanisms linking mood and meal are not understood.

Interestingly, appendicular muscle mass in depressive patients is decreased [103] and creatine augmentation of SSRI treatment has been discussed to be a promising therapeutic approach as shown in a 8-week double-blind placebo-controlled clinical trial at least in women [104]. Quercetin and the organoselenium compound m-trifluoromethyl-diphenyl diselenide are flavonoids found in plant foods and herbal medicines. Both of them have been shown to be effective in the modulation of serotonergic activity by attenuating mitochondrial MAO-A activity in the brain and attenuate oxidative stress by interrupting the generation of hydrogen peroxide accompanying the MAO-A reaction $[105,106]$.

Several reports indicate a high prevalence of folic acid deficiency among patients suffering from psychiatric conditions such as depression, bipolar disorder and cognitive dysfunction disorders [107]. Adequate levels of folate are essential for proper brain functioning [108]. Folate, with vitamins B12 and B6 as catalysing cofactors, influences cognitive performance and mood [108]. Treatment with vitamin B6, vitamin B12, and folic acid reduces the hazard of a major depressive episode compared with placebo among survivors of a stroke and reduces the risk to re-experience a major depressive episode for 7 years about 50\% [109]. Several trials have demonstrated efficacy of folic acid in the treatment of unipolar depression [110].

Epidemiologic and case-control data suggest that increased dietary intake of omega-3 long-chain polyunsaturated fatty acids may be of benefit in depression. In this context about 250 double-blind, placebo-controlled, randomized controlled trials have been performed, leading to the conclusion, that eicosapentaenoic acid might be more efficacious than docosahexaenoic acid in the treatment of depressive disorders [111]. Increased activity of acid sphingomyelinase by chronic stressors such as oxidative stress or TNFalpha could lead to the release of interleukin-1, elevated plasma corticosterone levels, the development of cardiovascular disease, increased activity of serum phospholipase A2, increase in the ratio of omega 6 fatty acids and low serum cholesterol in depressed patients [112]. S-adenosyl methionine is a naturally occurring molecule that serves as a methyl donor in human cellular metabolism. Preliminary data in 73 patients suggest that s-adenosyl methionine can be an effective, well-tolerated, and safe adjunctive treatment strategy for serotonin reuptake inhibitor nonresponders with major depressive disorder [113].

\section{Depression as a matter of dysregulated glutamate}

Glutamate regulates synaptic transmission and plasticity by activating ionotropic glutamate receptors ( $\alpha$-amino-3-hydroxy-5-methyl-4-isoxazolepropionic acid (AMPA) and $\mathrm{N}$-methyl-D-aspartate (NMDA) receptor) and metabotropic glutamate receptors (mGluR1 to mGluR8). The number and stability of these receptors at the synaptic membrane is an important factor in determining excitatory synaptic efficacy. Glutamate is cleared from the extracellular space by high-affinity excitatory amino acid transporters (EAATs), which are located on neighbouring glial cells (EAAT1 and EAAT2) and, to some extent, on neurons 
(EAAT3 and EAAT4) [114]. In glial cells, glutamate is converted into glutamine by glutamine synthetase. Glutamine is then transported back into the glutamatergic neuron, where it is hydrolysed into glutamate by glutaminase [115]. Owing to the lack of degradative enzymes in the synapse, uptake by EAATs is the primary mechanism through which the action of extracellular glutamate is terminated.

Studies have shown that drugs, which increase glutamate clearance, can prevent or reverse the effects of chronic stress and chronic glucocorticoid exposure and exert antidepressant effects in animal models of depression [116-118].

A single subanesthetic dose $(0.5 \mathrm{mg} / \mathrm{kg})$ of the $\mathrm{N}$-methyl-D-aspartate receptor antagonist ketamine causes a rapid antidepressant effect within hours in treatmentresistant patients with major depressive disorder [119]. The rapid antidepressant response after ketamine administration in treatment-resistant depressed patients suggests a possible new approach for treating mood disorders compared to the weeks or months required for standard medications [120]. As ketamine rapidly activates the mammalian target of rapamycin (mTOR) pathway, which is involved also in animal models of depression, this ubiquitous protein kinase, involved in protein synthesis and synaptic plasticity, might be involved in ketamine's rapid antidepressant effects. However, in an own study, we observed mood changes in patients using the mTOR inhibitor everolimus [121]. The NMDA receptor antagonist dextromethorphan has also been discussed as a potential rapid-acting antidepressant [122]. Then inhibition of substance P synthesis by FosB in the ventrolateral periaqueductal gray region results in reduced inhibition of escape behaviors mediated by $\gamma$-aminobutyric acid (GABA) in the nucleus accumbens [123]. Several lines of evidence suggest an antidepressant-like activity for 3-[(methyl-1,3-thiazol-4-yl)ethynyl]-pyridine, a highly selective, non-competitive antagonist of metabotropic glutamate receptors subtype 5 [124]. Recently it has been reported that the antimuscarinic agent, scopolamine, produces a rapid and robust antidepressant effect in currently depressed male and female patients with major depressive disorder or bipolar disorder $[125,126]$. Antidepressants have been shown to raise brain magnesium. Zinc and magnesium are potent inhibitors of the (NMDA) receptor complex. Recent data demonstrate that both zinc and magnesium, like other NMDA receptor antagonists, exhibit antidepressant-like activity in rodent screening tests and depression models. In a randomized controlled study in elderly patients with type II diabetes mellitus magnesium led to antidepressant like effects that were comparable to those of strong antidepressant drugs (i.e. imipramine $50 \mathrm{mg}$ /daily) [127]. In a double-blind, randomized and placebo-controlled study, Zinc supplementation was shown to improve mood states, reduce anger-hostility score and depression-dejection score [128].

\section{Depression as a neurodegenerative disorder}

Decreased hippocampal volumes have been found in a series of studies in humans exposed to chronic stress leading to the hypothesis that chronic stress can inhibit neurogenesis, retract dendritic processes lead to neuronal loss in the hippocampus [129, 130]. The majority of reported volumetric findings agree with reduced hippocampal volumes in depressive subjects [131].

Brain-derived neurotrophic factor (BDNF) regulates synaptic plasticity in neuronal networks involved in depressive behaviours $[132,133]$. Upregulation of BDNF may reverse stress-induced deficits in structural and synaptic plasticity in the adult brain, resulting in cognitive flexibility and an increased ability to adapt with environmental challenges that may precipitate or exacerbate depressive episodes. Recent studies demonstrate that BDNF levels are decreased in the blood of depressed patients and its levels are increased with antidepressant treatment [134-144]. Irrespective of the medication used, better treatment outcome was associated with higher BDNF plasmalevels [143]. Moreover, BDNF polymorphism and serum level have been connected with anxiety, risk of depression, neuroticism and serotonergic neurotransmission [145-149]. Augmentation of antidepressants with lithium is 
currently the best-evidenced augmentation therapy in the treatment of depressed patients who do not respond to antidepressants [150] and also lithium augmentation leads to a BDNF increase [143]. Neurotrophin-3 (NT-3) and nerve growth factor (NGF) also influence adult hippocampal neurogenesis and plasticity and thereby could contribute to stress-induced cellular and behavioral deficits, and antidepressant responses [151-155]. Other growth factors which have been shown to be changed in depression include glial cell line-derived neurotrophic factor (GDNF) and fibroblast growth factor-2 (FGF-2) [73, 156]. At least FGF-2 can be upregulated by antidepressant treatment [157]. It has been discussed recently, that BDNF might well signal through phosphoinositol dependent kinase 3, Akt and glycogen synthase kinase (GSK3) pathways [158], which has been supported also by our own data [159-161].

Additionally erythropoietin is involved in neuroplasticity and is a candidate for future treatment of depression. The investigators have demonstrated that a single dose of erythropoietin improves cognitive function and reduces neurocognitive processing of negative emotional information in healthy and depressed individuals similar to effects seen with conventional antidepressants [162]. Inositol as a constituent of the intracellular phosphatidyl-inositol second-messenger system, has shown some efficacy in small pilot studies of unipolar depression [163-165]. Finally, peripheral VGF expression is decreased in patients with MDD [166] and administration of recombinant VGF produces antidepressant behavioral responses in mice [167].

\section{References}

1 Van der Kooy K, van Hout H, Marwijk H, Marten H, Stehouwer C, Beekman A: Depression and the risk for cardiovascular diseases: systematic review and meta-analysis. Int J Geriatr Psychiatry 2007;22:613-626.

-2 Ramasubbu R, Patten SB: Effect of depression on stroke morbidity and mortality. Can J Psychiatry 2003;48:250-257.

-3 Green RC, Cupples LA, Kurz A, Auerbach S, Go R, Sadovnick D, Duara R, Kukull WA, Chui H, Edeki T, Griffith PA, Friedland RP, Bachman D, Farrer L: Depression as a risk factor for Alzheimer disease: the MIRAGE Study. Arch Neurol 2003;60:753-759.

4 Hesdorffer DC, Hauser WA, Annegers JF, Cascino G: Major depression is a risk factor for seizures in older adults. Ann Neurol 2000;47:246-249.

5 Nouwen A, Lloyd CE, Pouwer F: Depression and type 2 diabetes over the lifespan: a meta-analysis. Response to Mezuk et al. Diabetes Care 2009;32:e56-e57.

6 Penninx BW, Guralnik JM, Pahor M, Ferrucci L, Cerhan JR, Wallace RB, Havlik RJ: Chronically depressed mood and cancer risk in older persons. J Natl Cancer Inst 1998;90:1888-1893.

7 Keller MB, Hirschfeld RM, Demyttenaere K, Baldwin DS: Optimizing outcomes in depression: focus on antidepressant compliance. Int Clin Psychopharmacol 2002;17:265-271.

-8 Hendrickx H, McEwen BS, Ouderaa F: Metabolism, mood and cognition in aging: the importance of lifestyle and dietary intervention. Neurobiol Aging 2005;26:1-5.

9 Shelton RC, Miller AH: Eating ourselves to death (and despair): the contribution of adiposity and inflammation to depression. Prog Neurobiol 2010;91:275-299.

10 Bouwman V, Adriaanse MC, van 't Riet E, Snoek FJ, Dekker JM, Nijpels G: Depression, anxiety and glucose metabolism in the general dutch population: the new Hoorn study. PLoS One 2010;5:e9971.

11 McIntyre RS, Soczynska JK, Konarski JZ, Woldeyohannes HO, Law CW, Miranda A, Fulgosi D, Kennedy SH: Should Depressive Syndromes Be Reclassified as "Metabolic Syndrome Type II"? Ann Clin Psychiatry 2007;19:257-266.

12 Wexler DJ, Porneala B, Chang Y, Huang ES, Huffman JC, Grant RW: Diabetes differentially affects depression and self-rated health by age in the US. Diabetes Care 2012;35:1575-1577.

13 Gois C, Akiskal H, Akiskal K, Figueira ML: The relationship between temperament, diabetes and depression. J Affect Disord 2012;142:S67-71.

14 Chaudhri OB, Wynne K, Bloom SR: Can gut hormones control appetite and prevent obesity? Diabetes Care 2008;31:S284-289. 
15 Häfner S, Baumert J, Emeny RT, Lacruz ME, Thorand B, Herder C, Koenig W, Rupprecht R, Ladwig KH: Sleep disturbances and depressed mood: a harmful combination associated with increased leptin levels in women with normal weight. Biol Psychol 2012;89:163-169.

16 Garza JC, Guo M, Zhang W, Lu XY: Leptin restores adult hippocampal neurogenesis in a chronic unpredictable stress model of depression and reverses glucocorticoid-induced inhibition of GSK-3 $\beta / \beta$ catenin signaling. Mol Psychiatry 2012;17:790-808.

17 Krugel U, Schraft T, Kittner H, Kiess W, Illes P: Basal and feeding-evoked dopamine release in the rat nucleus accumbens is depressed by leptin. Eur J Pharmacol 2003;482:185-187.

18 Fulton S, Pissios P, Manchon RP, Stiles L, Frank L, Pothos EN, Maratos-Flier E, Flier JS: Leptin regulation of the mesoaccumbens dopamine pathway. Neuron 2006;51:811-822.

19 Hommel JD, Trinko R, Sears RM, Georgescu D, Liu ZW, Gao XB, Thurmon JJ, Marinelli M, DiLeone RJ: Leptin receptor signaling in midbrain dopamine neurons regulates feeding. Neuron 2006;51:801-810.

20 Lutter M, Nestler EJ: Homeostatic and hedonic signals interact in the regulation of food intake. J Nutr 2009;139:629-632.

21 Kluge M, Schüssler P, Dresler M, Schmidt D, Yassouridis A, Uhr M, Steiger A: Effects of ghrelin on psychopathology, sleep and secretion of cortisol and growth hormone in patients with major depression. J Psychiatr Res 2011;45:421-426.

22 Lutter M, Sakata I, Osborne-Lawrence S, Rovinsky SA, Anderson JG, Jung S, Birnbaum S, Yanagisawa M, Elmquist JK, Nestler EJ, Zigman JM: The orexigenic hormone ghrelin defends against depressive symptoms of chronic stress. Nat Neurosci 2008;11:752-753.

23 Schellekens H, Finger BC, Dinan TG, Cryan JF: Ghrelin signalling and obesity: at the interface of stress, mood and food reward. Pharmacol Ther 2012;135:316-326.

24 Koliaki C, Kokkinos A, Tentolouris N, Katsilambros N: The effect of ingested macronutrients on postprandial ghrelin response: a critical review of existing literature data. Int J Pept 2010;2010. pii:710852.

25 Aberg MA, Aberg ND, Hedbacker H, Oscarsson J, Eriksson PS: Peripheral infusion of IGF-I selectively induces neurogenesis in the adult rat hippocampus. J Neurosci 2000;20:2896-2903.

-26 Trejo JL, Carro E, Torres-Aleman I: Circulating insulin-like growth factor I mediates exercise-induced increases in the number of new neurons in the adult hippocampus. J Neurosci 2001;21:1628-1634.

27 Cline BH, Steinbusch HW, Malin D, Revishchin AV, Pavlova GV, Cespuglio R, Strekalova T: The neuronal insulin sensitizer dicholine succinate reduces stress-induced depressive traits and memory deficit: possible role of insulin-like growth factor 2. BMC Neurosci 2012;13:110.

28 Anderson MF, Aberg MA, Nilsson M, Eriksson PS: Insulin-like growth factor-I and neurogenesis in the adult mammalian brain. Brain Res Dev Brain Res 2002;134:115-122.

-29 Hoshaw BA, Malberg JE, Lucki I: Central administration of IGF-I and BDNF leads to long-lasting antidepressant-like effects. Brain Res 2005;1037:204-208.

-30 Malberg JE, Platt B, Rizzo SJ, Ring RH, Lucki I, Schechter LE, Rosenzweig-Lipson S: Increasing the levels of insulin-like growth factor-I by an IGF binding protein inhibitor produces anxiolytic and antidepressant-like effects. Neuropsychopharmacology 2007;32:2360-2368.

-31 Becker C, Zeau B, Rivat C, Blugeot A, Hamon M, Benoliel JJ: Repeated social defeat-induced depression-like behavioral and biological alterations in rats: involvement of cholecystokinin. Mol Psychiatry 2008;13:10791092.

-32 Ströhle A, Romeo E, di Michele F, Pasini A, Hermann B, Gajewsky G, Holsboer F, Rupprecht R: Induced panic attacks shift gamma-aminobutyric acid type A receptor modulatory neuroactive steroid composition in patients with panic disorder: preliminary results. Arch Gen Psychiatry 2003;60:161-168.

-33 Arey RN, Enwright JF 3rd, Spencer SM, Falcon E, Ozburn AR, Ghose S, Tamminga C, McClung CA: An important role for Cholecystokinin, a CLOCK target gene, in the development and treatment of manic-like behaviors. Mol Psychiatry 2013; doi: 10.1038/mp.2013.47.

-34 Roesler R, Henriques JA, Schwartsmann G: Gastrin-releasing peptide receptor as a molecular target for psychiatric and neurological disorders. CNS Neurol Disord Drug Targets 2006;5:197-204.

-35 Horacek J, Kuzmiakova M, Hoschl C, Andel M, Bahbonh R: The relationship between central serotonergic activity and insulin sensitivity in healthy volunteers. Psychoneuroendocrinology 1999;24:785-797.

-36 McCarty MF: Longevity effect of chromium picolinate - 'rejuvenation' of hypothalamic function? Med Hypotheses 1994;43:253-265. 
37 McLeod MN, Gaynes BN, Golden RN: Chromium potentiation of antidepressant pharmacotherapy for dysthymic disorder in 5 patients. J Clin Psychiatry 1999;60:237-240.

38 McLeod MN, Golden RN: Chromium treatment of depression. Int J Neuropsychopharmacol 2000;3:311314.

39 Davidson JR, Abraham K, Connor KM, McLeod MN: Effectiveness of chromium in atypical depression: a placebo-controlled trial. Biol Psychiatry 2003;53:261-264.

40 Gentleman SM, Falkai P, Bogerts B, Herrero MT, Polak JM, Roberts GW: Distribution of galanin-like immunoreactivity in the human brain. Brain Res 1989;505:311-315.

41 Kozlovsky N, Matar MA, Kaplan Z, Zohar J, Cohen H: The role of the galaninergic system in modulating stress-related responses in an animal model of posttraumatic stress disorder. Biol Psychiatry 2009;65:383391.

-42 Tatemoto K, Carlquist M, Mutt V: Neuropeptide Y -- a novel brain peptide with structural similarities to peptide YY and pancreatic polypeptide. Nature 1982;296:659-660.

43 Brothers SP, Wahlestedt C: Therapeutic potential of neuropeptide Y (NPY) receptor ligands. EMBO Mol Med 2010;2:429-439.

44 Wu G, Feder A, Wegener G, Bailey C, Saxena S, Charney D, Mathé AA: Central functions of neuropeptide Y in mood and anxiety disorders. Expert Opin Ther Targets 2011;15:1317-1331.

45 Liao GY, An JJ, Gharami K, Waterhouse EG, Vanevski F, Jones KR, Xu B: Dendritically targeted Bdnf mRNA is essential for energy balance and response to leptin. Nat Med 2012;18:564-571.

46 Holsboer F, Ising M: Stress hormone regulation: biological role and translation into therapy. Annu Rev Psychol 2010;61:81-109.

47 Feder A, Nestler EJ, Charney DS: Psychobiology and molecular genetics of resilience. Nat Rev Neurosci 2009;10:446-457.

48 Kling MA, Coleman VH, Schulkin J: Glucocorticoid inhibition in the treatment of depression: can we think outside the endocrine hypothalamus? Depress Anxiety 2009;26:641-649.

49 Boswell EB, Anfinson TH, Nemeroff CB: Depression associated with endocrine disorders; In Robertson MM, Katona CLE (eds): Depression and physical illness. England: Wiley, Chichester, 1997, pp 256-292.

50 Bahls SC, de Carvalho GA : The relation between thyroid function and depression: a review. Rev Bras Psiquiatr 2004;26:41-49.

51 Cleare AJ, McGregor A, O'Keane V: Neuroendocrine evidence for an association between hypothyroidism, reduced central 5-HT activity and depression. Clin Endocrinol 1995;43:713-719.

52 Frey A, Lampert A, Dietz K, Striebich S, Locher C, Fedorenko O, Möhle R, Gallinat J, Lang F, Lang UE: Thyrotropin serum concentrations in healthy volunteers are associated with depression-related personality traits. Neuropsychobiology 2007;56:123-126.

53 Altshuler LL, Bauer M, Frye MA, Gitlin MJ, Mintz J, Szuba MP, Leight KL, Whybrow PC: Does thyroid supplementation accelerate tricyclic antidepressant response? A review and meta-analysis of the literature. Am J Psychiatry 2001;158:1617-1622.

54 Carvalho AF, Machado JR, Cavalcante JL: Augmentation strategies for treatment-resistant depression. Curr Opin Psychiatry 2009;22:7-12.

55 Dayan CM, Panicker V: Novel insights into thyroid hormones from the study of common genetic variation. Nat Rev Endocrinol 2009;5:211-218.

56 Nemeroff CB, Goldschmidt-Clermont PJ: Heartache and heartbreak--the link between depression and cardiovascular disease. Nat Rev Cardiol 2012;9:526-539.

57 Lippi G, Montagnana M, Favaloro EJ, Franchini M: Mental depression and cardiovascular disease: a multifaceted, bidirectional association. Semin Thromb Hemost 2009;35:325-333.

58 Tiemeier H, van Dijck W, Hofman A, Witteman JC, Stijnen T, Breteler MM: Relationship between atherosclerosis and late-life depression: the Rotterdam Study. Arch Gen Psychiatry 2004;61:369-376.

59 Cizza G, Ronsaville DS, Kleitz H, Eskandari F, Mistry S, Torvik S, Sonbolian N, Reynolds JC, Blackman MR, Gold PW, Martinez PE; P.O.W.E.R (Premenopausal, Osteopenia/Osteoporosis, Women, Alendronate, Depression) Study Group: Clinical subtypes of depression are associated with specific metabolic parameters and circadian endocrine profiles in women: the power study. PLoS One 2012;7:e28912.

60 Kabir AA, Srinivasan SR, Sultana A, Chen W, Wei CY, Berenson GS: Association between depression and intima-media thickness of carotid bulb in asymptomatic young adults. Am J Med 2009;122:1151.e1-8. 


\section{Cellular Physiology Cell Physiol Biochem 2013;31:761-777

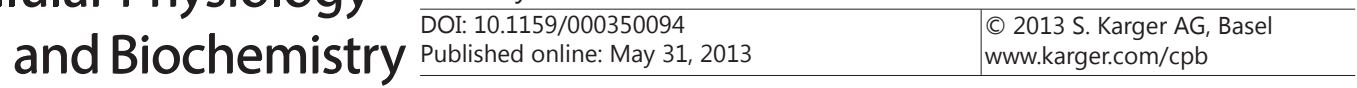

Lang/Borgwardt: Causes of Depression

61 Smith PJ, Blumenthal JA, Babyak MA, Doraiswamy PM, Hinderliter A, Hoffman BM, Waugh R, Sherwood A: Intima-media thickness and age of first depressive episode. Biol Psychol 2009;80:361-364.

62 Baghai TC, Varallo-Bedarida G, Born C, Häfner S, Schüle C, Eser D, Rupprecht R, Bondy B, von Schacky C: Major depressive disorder is associated with cardiovascular risk factors and low Omega-3 Index. J Clin Psychiatry 2011;72:1242-1247.

-63 Geiser F, Meier C, Wegener I, Imbierowicz K, Conrad R, Liedtke R, Oldenburg J, Harbrecht U: Association between anxiety and factors of coagulation and fibrinolysis. Psychother Psychosom 2008;77:377-383.

64 Nemeroff CB, Musselman DL: Are platelets the link between depression and ischemic heart disease? Am Heart J 2000;140:57-62.

-65 Chrapko WE, Jurasz P, Radomski MW, Lara N, Archer SL, Le Mellédo JM: Decreased platelet nitric oxide synthase activity and plasma nitric oxide metabolites in major depressive disorder. Biol Psychiatry 2004;56:129-134.

66 Stafford L, Berk M: The use of statins after a cardiac intervention is associated with reduced risk of subsequent depression: proof of concept for the inflammatory and oxidative hypotheses of depression? J Clin Psychiatry 2011;72:1229-1235.

67 Portella MJ, de Diego-Adeliño J, Ballesteros J, Puigdemont D, Oller S, Santos B, Alvarez E, Artigas F, Pérez V: Can we really accelerate and enhance the selective serotonin reuptake inhibitor antidepressant effect? a randomized clinical trial and a meta-analysis of pindolol in nonresistant depression. J Clin Psychiatry 2011;72:962-969.

68 Jin K, Zhu Y, Sun Y, Mao XO, Xie L, Greenberg DA: Vascular endothelial growth factor (VEGF) stimulates neurogenesis in vitro and in vivo. Proc Natl Acad Sci USA 2002;99:11946-11950.

69 Storkebaum E, Lambrechts D, Carmeliet P: VEGF: once regarded as a specific angiogenic factor, now implicated in neuroprotection. Bioessays 2004;26:943-954.

-70 Warner-Schmidt JL, Duman RS: VEGF is an essential mediator of the neurogenic and behavioral actions of antidepressants. Proc Natl Acad Sci USA 2007;104:4647-4652.

-71 Altar CA, Boylan CB, Jackson C, Hershenson S, Miller J, Wiegand SJ, Lindsay RM, Hyman C: Brain-derived neurotrophic factor augments rotational behavior and nigrostriatal dopamine turnover in vivo. Proc Natl Acad Sci USA 1992;89:11347-11351.

72 Iga JI, Ueno SI, Yamauchi K, Numata S, Tayoshi-Shibuya S, Kinouchi S, Nakataki M, Song H, Hokoishi K, Tanabe H, Sano A, Ohmori T: Gene expression and association analysis of vascular endothelial growth factor in major depressive disorder. Prog Neuropsychopharmacol Biol Psychiatry 2007;31:658-663.

73 Kahl KG, Bens S, Ziegler K, Rudolf S, Kordon A, Dibbelt L, Schweiger U: Angiogenic factors in patients with current major depressive disorder comorbid with borderline personality disorder. Psychoneuroendocrinology 2009;34:353-357.

74 Dantzer R: Cytokine, sickness behavior, and depression. Immunol Allergy Clin North Am 2009;29:247-64.

75 Liu Y, Ho RC, Mak A: Interleukin (IL)-6, tumour necrosis factor alpha (TNF- $\alpha$ ) and soluble interleukin-2 receptors (sIL-2R) are elevated in patients with major depressive disorder: a meta-analysis and metaregression. J Affect Disord 2012;139:230-239.

-76 Dowlati Y, Herrmann N, Swardfager W, Liu H, Sham L, Reim EK, Lanctôt KL: A meta-analysis of cytokines in major depression. Biol Psychiatry 2010;67:446-457.

-77 Garvey MA, Perlmutter SJ, Allen AJ, Hamburger S, Lougee L, Leonard HL, Witowski ME, Dubbert B, Swedo SE: A pilot study of penicillin prophylaxis for neuropsychiatric exacerbations triggered by streptococcal infections. Biol Psychiatry 1999;45:1564-1571.

-78 Gallagher PJ, Castro V, Fava M, Weilburg JB, Murphy SN, Gainer VS, Churchill SE, Kohane IS, Iosifescu DV, Smoller JW, Perlis RH: Antidepressant Response in Patients With Major Depression Exposed to NSAIDs: A Pharmacovigilance Study. Am J Psychiatry 2012;169:1065-1072.

79 Celano CM, Freudenreich O, Fernandez-Robles C, Stern TA, Caro MA, Huffman JC: Depressogenic effects of medications: a review. Dialogues Clin Neurosci 2011;13:109-125.

80 De Berardis D, Conti CM, Serroni N, Moschetta FS, Olivieri L, Carano A, Salerno RM, Cavuto M, Farina B, Alessandrini M, Janiri L, Pozzi G, Di Giannantonio M: The effect of newer serotonin-noradrenalin antidepressants on cytokine production: a review of the current literature. Int J Immunopathol Pharmacol 2010;23:417-422. 


\section{Cellular Physiology Cell Physiol Biochem 2013;31:761-777

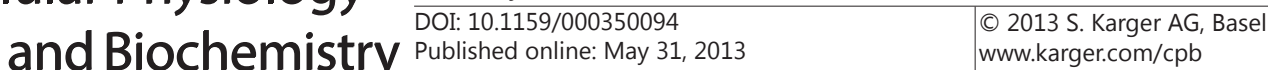

Lang/Borgwardt: Causes of Depression

81 Bell C, Abrams J, Nutt D: Tryptophan depletion and its implications for psychiatry. Br J Psychiatry 2001;178:399-405.

82 Kamb ML, Murphy JJ, Jones JL, Caston JC, Nederlof K, Horney LF, Swygert LA, Falk H, Kilbourne EM: Eosinophilia-myalgia syndrome in L -tryptophan-exposed patients. JAMA 1992;267:77-82.

83 Capuron L, Gumnick JF, Musselman DL, Lawson DH, Reemsnyder A, Nemeroff CB, Miller AH: Neurobehavioral effects of interferon-alpha in cancer patients: phenomenology and paroxetine responsiveness of symptom dimensions. Neuropsychopharmacology 2002;26:643-652.

-84 Müller N, Schwarz MJ, Dehning S, Douhe A, Cerovecki A, Goldstein-Müller B, Spellmann I, Hetzel G, Maino K, Kleindienst N, Möller HJ, Arolt V, Riedel M: The cyclooxygenase-2 inhibitor celecoxib has therapeutic effects in major depression: results of a double-blind, randomized, placebo controlled, add-on pilot study to reboxetine. Mol Psychiatry 2006;11:680-684.

85 Akhondzadeh S, Jafari S, Raisi F, Nasehi AA, Ghoreishi A, Salehi B, Mohebbi-Rasa S, Raznahan M, Kamalipour A: Clinical trial of adjunctive celecoxib treatment in patients with major depression: a double blind and placebo controlled trial. Depress Anxiety 2009;26:607-611.

86 Nery FG, Monkul ES, Hatch JP, Fonseca M, Zunta-Soares GB, Frey BN, Bowden CL, Soares JC: Celecoxib as an adjunct in the treatment of depressive or mixed episodes of bipolar disorder: a double-blind, randomized, placebo-controlled study. Hum Psychopharmacol 2008;23:87-94.

87 Guo JY, Li CY, Ruan YP, Sun M, Qi XL, Zhao BS, Luo F: Chronic treatment with celecoxib reverses chronic unpredictable stress-induced depressive-like behavior via reducing cyclooxygenase-2 expression in rat brain. Eur J Pharmacol 2009;612:54-60.

-88 Gárate I, Garcia-Bueno B, Madrigal JL, Caso JR, Alou L, Gomez-Lus ML, Micó JA, Leza JC: Stress-induced neuroinflammation: role of the Toll-like receptor-4 pathway. Biol Psychiatry 2013;73:32-43.

89 Kumar B, Kuhad A, Chopra K: Neuropsychopharmacological effect of sesamol in unpredictable chronic mild stress model of depression: behavioral and biochemical evidences. Psychopharmacology (Berl) 2011;214:819-828.

90 Lau BW, Ren C, Yang J, Yan SW, Chang RC, Pu M, So KF: Light deprivation induces depression-like behavior and suppresses neurogenesis in diurnal mongolian gerbil (Meriones unguiculatus). Cell Transplant 2011;20:871-881.

91 Zajecka J, Schatzberg A, Stahl S, Shah A, Caputo A, Post A: Efficacy and safety of agomelatine in the treatment of major depressive disorder: a multicenter, randomized, double-blind, placebo-controlled trial. J Clin J Psychiatry Neurosci 2012;37:7-16.

92 Ljubicić D, Stipcević T, Pivac N, Jakovljević M, Mück-Seler D: The influence of daylight exposure on platelet 5-HT levels in patients with major depression and schizophrenia. J Photochem Photobiol B 2007;89:63-69.

-93 Ubbenhorst A, Striebich S, Lang F, Lang UE: Exploring the relationship between vitamin D and basic personality traits. Psychopharmacology (Berl) 2011;215:733-737.

$\$ 94$ Papadopoulos FC: Season as a possible confounding factor in reduced brain serotonin turnover following selective serotonin reuptake inhibitor therapy. Arch Gen Psychiatry 2008;65:1224-1225.

$\$ 95$ Thorn L, Evans P, Cannon A, Hucklebridge F, Clow A: Seasonal differences in the diurnal pattern of cortisol secretion in healthy participants and those with self-assessed seasonal affective disorder. Psychoneuroendocrinology 2011;36:816-823.

-96 Molendijk ML, Haffmans JP, Bus BA, Spinhoven P, Penninx BW, Prickaerts J, Oude Voshaar RC, Elzinga BM: Serum BDNF concentrations show strong seasonal variation and correlations with the amount of ambient sunlight. PLoS One 2012; 7:e48046.

-97 Goodman A, Paskins J, Mackett R: Day length and weather effects on children's physical activity and participation in play, sports, and active travel. J Phys Act Health 2012;9:1105-1116.

98 Wright KP, Rogers NL: Endogenous versus exogenous effects of melatonin; Pandi-Perumal, Cardinali (Eds.), Melatonin: from molecules to therapy, Nova Science Publishers, New York, 2007, pp 547-569.

-99 Gonciarz M, Bielański W, Partyka R, Brzozowski T, Konturek PC, Eszyk J, Celiński K, Reiter RJ, Konturek SJ: Plasma insulin, leptin, adiponectin, resistin, ghrelin, and melatonin in nonalcoholic steatohepatitis patients treated with melatonin. J Pineal Res 2013;54:154-161.

100 Srinivasan V, Ohta Y, Espino J, Pariente JA, Rodriguez AB, Mohamed M, Zakaria R: Metabolic syndrome, its pathophysiology and the role of melatonin. Recent Pat Endocr Metab Immune Drug Discov 2013;7:11-25. 
101 Martiny K, Refsgaard E, Lund V, Lunde M, Sørensen L, Thougaard B, Lindberg L, Bech P: A 9-week randomized trial comparing a chronotherapeutic intervention (wake and light therapy) to exercise in major depressive disorder patients treated with duloxetine. J Clin Psychiatry 2012;73:1234-1242.

102 Sanhueza C, Ryan L, Foxcroft DR: Diet and the risk of unipolar depression in adults: systematic review of cohort studies. J Hum Nutr Diet 2013;26:56-70.

103 Kim NH, Kim HS, Eun CR, Seo JA, Cho HJ, Kim SG, Choi KM, Baik SH, Choi DS, Park MH, Han C, Kim NH: Depression is associated with sarcopenia, not central obesity, in elderly korean men. J Am Geriatr Soc 2011;59:2062-2068.

104 Lyoo IK, Yoon S, Kim TS, Hwang J, Kim JE, Won W, Bae S, Renshaw PF: A randomized, double-blind placebocontrolled trial of oral creatine monohydrate augmentation for enhanced response to a selective serotonin reuptake inhibitor in women with major depressive disorder. Am J Psychiatry 2012;169:937-945.

105 Yoshino S, Hara A, Sakakibara H, Kawabata K, Tokumura A, Ishisaka A, Kawai Y, Terao J: Effect of quercetin and glucuronide metabolites on the monoamine oxidase-A reaction in mouse brain mitochondria. Nutrition 2011;27:847-852.

106 Brüning CA, Souza AC, Gai BM, Zeni G, Nogueira CW: Antidepressant-like effect of m-trifluoromethyldiphenyl diselenide in the mouse forced swimming test involves opioid and serotonergic systems. Eur J Pharmacol 2011;658:145-149.

107 Reynolds EH: Folic acid, ageing, depression, and dementia. BMJ 2002;324:1512-1515.

108 Mischoulon D, Raab MF: The role of folate in depression and dementia. J Clin Psychiatry 2007;68:28-33.

109 Almeida OP, Marsh K, Alfonso H, Flicker L, Davis TM, Hankey GJ: B-vitamins reduce the long-term risk of depression after stroke: The VITATOPS-DEP trial. Ann Neurol 2010;68:503-510.

110 Lazarou C, Kapsou M: The role of folic acid in prevention and treatment of depression: an overview of existing evidence and implications for practice. Complement Ther Clin Pract 2010;16:161-166.

111 Martins JG, Bentsen H, Puri BK: Eicosapentaenoic acid appears to be the key omega-3 fatty acid component associated with efficacy in major depressive disorder: a critique of Bloch and Hannestad and updated meta-analysis. Mol Psychiatry 2012;17:1144-1149.

112 Kornhuber J, Tripal P, Reichel M, Mühle C, Rhein C, Muehlbacher M, Groemer TW, Gulbins E: Functional Inhibitors of Acid Sphingomyelinase (FIASMAs): a novel pharmacological group of drugs with broad clinical applications. Cell Physiol Biochem 2010;26:9-20.

113 Papakostas GI, Mischoulon D, Shyu I, Alpert JE, Fava M: S-adenosyl methionine (SAMe) augmentation of serotonin reuptake inhibitors for antidepressant nonresponders with major depressive disorder: a doubleblind, randomized clinical trial. Am J Psychiatry 2010;167:942-948.

114 O'Shea RD: Roles and regulation of glutamate transporters in the central nervous system. Clin Exp Pharmacol Physiol 2002;29:1018-1023.

115 Erecinska M, Silver IA: Metabolism and role of glutamate in mammalian brain. Prog Neurobiol 1990;35:245-296.

116 Banasr M, Chowdhury GM, Terwilliger R, Newton SS, Duman RS, Behar KL, Sanacora G: Glial pathology in an animal model of depression: reversal of stress-induced cellular, metabolic and behavioural deficits by the glutamate-modulating drug riluzole. Mol Psychiatry 2010;15:501-511.

117 Mineur YS, Picciotto MR, Sanacora G: Antidepressant-like effects of ceftriaxone in male C57BL/56J mice. Biol Psychiatry 2007;61:250-252.

118 Gourley SL, Espitia JW, Sanacora G, Taylor JR: Utility and antidepressant-like properties of oral riluzole in mice. Psychopharmacology 2012;219:805-814.

119 Diazgranados N, Ibrahim L, Brutsche NE, Newberg A, Kronstein P, Khalife S, Kammerer WA, Quezado Z, Luckenbaugh DA, Salvadore G, Machado-Vieira R, Manji HK, Zarate CA Jr: A randomized add-on trial of an N-methyl-D-aspartate antagonist in treatment-resistant bipolar depression. Arch Gen Psychiatry 2010;67:793-802.

120 Li N, Lee B, Liu RJ, Banasr M, Dwyer JM, Iwata M, Li XY, Aghajanian G, Duman RS: mTOR-dependent synapse formation underlies the rapid antidepressant effects of NMDA antagonists. Science 2010;329:959-964.

121 Lang UE, Heger J, Willbring M, Domula M, Matschke K, Tugtekin SM: Immunosuppression using the mammalian target of rapamycin (mTOR) inhibitor everolimus: pilot study shows significant cognitive and affective improvement. Transplant Proc 2009;41:4285-4288.

122 Lauterbach EC: Dextromethorphan as a potential rapid-acting antidepressant. Med Hypotheses 2011;76:717-719. 
123 Thase ME: Molecules That Mediate Mood. N Engl J Med 2007;357:2400-2402.

124 Pałucha A, Brański P, Szewczyk B, Wierońska JM, Kłak K, Pilc A: Potential antidepressant-like effect of MTEP, a potent and highly selective mGluR5 antagonist. Pharmacol Biochem Behav 2005;81:901-906.

125 Drevets WC, Furey ML: Replication of scopolamine's antidepressant efficacy in major depressive disorder: a randomized, placebo-controlled clinical trial. Biol Psychiatry 2010;67:432-438.

126 Furey ML, Drevets WC: Antidepressant efficacy of the antimuscarinic drug scopolamine: a randomized, placebo-controlled clinical trial. Arch Gen Psychiatry 2006;63:1121-1129.

127 Barragán-Rodríguez L, Rodríguez-Morán M, Guerrero-Romero F: Efficacy and safety of oral magnesium supplementation in the treatment of depression in the elderly with type 2 diabetes: a randomized, equivalent trial. Magnes Res 2008;21:218-223.

128 Sawada T, Yokoi K: Effect of zinc supplementation on mood states in young women: a pilot study. Eur J Clin Nutr 2010;64:331-333.

129 Schmidt HD, Duman RS: The role of neurotrophic factors in adult hippocampal neurogenesis, antidepressant treatments and animal models of depressive-like behavior. Behav Pharmacol 2007;18:391418.

130 Schmidt HD, Shelton RC, Duman RS: Functional Biomarkers of Depression: Diagnosis, Treatment, and Pathophysiology. Neuropsychopharmacology 2011;36:2375-2394.

131 Campbell S, MacQueen G: An update on regional brain volume differences associated with mood disorders. Curr Opin Psychiatry 2006;19:25-33.

132 Pittenger C, Duman RS: Stress, depression, and neuroplasticity: a convergence of mechanisms. Neuropsychopharmacology 2007;33:88-109.

133 Schinder AF, Poo M: The neurotrophin hypothesis for synaptic plasticity. Trends Neurosci 2000;23:639645.

$\$ 134$ Aydemir 0, Deveci A, Taneli F: The effect of chronic antidepressant treatment on serum brain-derived neurotrophic factor levels in depressed patients: a preliminary study. Prog Neuropsychopharmacol Biol Psychiatry 2005;29:261-265.

135 Gervasoni N, Aubry JM, Bondolfi G, Osiek C, Schwald M, Bertschy G, Karege F: Partial normalization of serum brain-derived neurotrophic factor in remitted patients after a major depressive episode. Neuropsychobiology 2005;51:234-238.

136 Shimizu E, Hashimoto K, Okamura N, Koike K, Komatsu N, Kumakiri C, Nakazato M, Watanabe H, Shinoda N, Okada S, Iyo M: Alterations of serum levels of brain-derived neurotrophic factor (BDNF) in depressed patients with or without antidepressants. Biol Psychiatry 2003;54:70-75.

137 Lee AH, Lange C, Ricken R, Hellweg R, Lang UE: Reduced brain-derived neurotrophic factor serum concentrations in acute schizophrenic patients increase during antipsychotic treatment. J Clin Psychopharmacol 2011;31:334-336.

138 Karege F, Perret G, Bondolfi G, Schwald M, Bertschy G, Aubry JM: Decreased serum brain-derived neurotrophic factor levels in major depressed patients. Psychiatry Res 2002;109:143-148.

139 Kim YK, Lee HP, Won SD, Park EY, Lee HY, Lee BH, Lee SW, Yoon D, Han C, Kim DJ, Choi SH: Low plasma BDNF is associated with suicidal behavior in major depression. Prog Neuropsychopharmacol Biol Psychiatry 2007;31:78-85.

140 Lee BH, Kim H, Park SH, Kim YK: Decreased plasma BDNF level in depressive patients. J Affect Disord 2006;101:239-244.

141 Brunoni AR, Lopes M, Fregni F: A systematic review and meta-analysis of clinical studies on major depression and BDNF levels: implications for the role of neuroplasticity in depression. Int J Neuropsychopharmacol 2008;11:1169-1180.

142 Deuschle M, Gilles M, Scharnholz B, Lederbogen F, Lang UE, Hellweg R: Changes of Serum Concentrations of Brain-Derived Neurotrophic Factor (BDNF) during Treatment with Venlafaxine and Mirtazapine: Role of Medication and Response to Treatment. Pharmacopsychiatry 2013;46:54-58.

143 Ricken R, Adli M, Lange C, Krusche E, Koehler S, Hellweg R, Nase S, Richter C, Bschor T, Steinacher B, Rapp M, Borgwardt S, Lang UE: Reduced BDNF serum concentrations in acute depressive patients increase during lithium augmentation of antidepressants. J Clin Psychopharmacol 2013; in press.

144 Sen S, Duman R, Sanacora G: Serum brain-derived neurotrophic factor, depression, and antidepressant medications: meta-analyses and implications. Biol Psychiatry 2008;64:527-532. 
145 Lang UE, Günther L, Scheuch K, Klein J, Eckhart S, Hellweg R, Danker-Hopfe H, Oehler J: Higher BDNF concentrations in the hippocampus and cortex of an aggressive mouse strain. Behav Brain Res 2009;197:246-249.

146 Lang UE, Hellweg R, Gallinat J: Association of BDNF serum concentrations with central serotonergic activity: evidence from auditory signal processing. Neuropsychopharmacology 2005;30:1148-1153.

147 Lang UE, Hellweg R, Gallinat J: BDNF serum concentrations in healthy volunteers are associated with depression-related personality traits. Neuropsychopharmacology 2004;29:795-798.

148 Lang UE, Hellweg R, Kalus P, Bajbouj M, Lenzen KP, Sander T, Kunz D, Gallinat J: Association of a functional BDNF polymorphism and anxiety-related personality traits. Psychopharmacology (Berl) 2005;180:95-99.

149 Lang UE, Hellweg R, Seifert F, Schubert F, Gallinat J: Correlation between serum brain-derived neurotrophic factor level and an in vivo marker of cortical integrity. Biol Psychiatry 2007;62:530-535.

150 Bauer M, Adli M, Bschor T, Pilhatsch M, Pfennig A, Sasse J, Schmid R, Lewitzka U: Lithium's emerging role in the treatment of refractory major depressive episodes: augmentation of antidepressants. Neuropsychobiology 2010;62:36-42.

151 Hellweg R, Lang UE, Nagel M, Baumgartner A: Subchronic treatment with lithium increases nerve growth factor content in distinct brain regions of adult rats. Mol Psychiatry 2002;7:604-608.

152 Hock C, Heese K, Muller-Spahn F, Huber P, Riesen W, Nitsch RM, Otten U: Increased cerebrospinal fluid levels of neurotrophin 3 (NT-3) in elderly patients with major depression. Mol Psychiatry 2000;5:510-513.

153 Lang UE, Hellweg R, Bajbouj M, Gaus V, Sander T, Gallinat J: Gender-dependent association of a functional NGF polymorphism with anxiety-related personality traits. Pharmacopsychiatry 2008;41:196-199.

154 Smith MA, Makino S, Altemus M, Michelson D, Hong SK, Kvetnansky R, Post RM: Stress and antidepressants differentially regulate neurotrophin 3 mRNA expression in the locus coeruleus. Proc Natl Acad Sci USA 1995;92:8788-8792.

155 von Richthofen S, Lang UE, Hellweg R: Effects of different kinds of acute stress on nerve growth factor content in rat brain. Brain Res 2003;987:207-213.

156 Rosa AR, Frey BN, Andreazza AC, Cereser KM, Cunha AB, Quevedo J, Santin A, Gottfried C, Gonçalves CA, Vieta E, Kapczinski F: Increased serum glial cell line-derived neurotrophic factor immunocontent during manic and depressive episodes in individuals with bipolar disorder. Neurosci Lett 2006;407:146-150.

157 Evans SJ, Choudary PV, Neal CR, JZ, Vawter MP, Tomita H, Lopez JF, Thompson RC, Meng F, Stead JD, Walsh DM, Myers RM, Bunney WE, Watson SJ, Jones EG, Akil H: Dysregulation of the fibroblast growth factor system in major depression. Proc Natl Acad Sci USA 2004;101:15506-15511.

158 Beaulieu JM: A role for Akt and glycogen synthase kinase-3 as integrators of dopamine and serotonin neurotransmission in mental health. Psychopharmacol 2010;30:135-144.

159 Ackermann TF, Hörtnagl H, Wolfer DP, Colacicco G, Sohr R, Lang F, Hellweg R, Lang UE: Phosphatidylinositide dependent kinase deficiency increases anxiety and decreases GABA and serotonin abundance in the amygdala. Cell Physiol Biochem 2008;22:735-744.

160 Ackermann TF, Kempe DS, Lang F, Lang UE: Hyperactivity and enhanced curiosity of mice expressing PKB/ SGK-resistant glycogen synthase kinase-3 (GSK-3). Cell Physiol Biochem 2010;25:775-786.

161 Lang UE: Impairment of phosphatidylinositol 3-kinase signaling in schizophrenia: state or trait? Am J Psychiatry 2010;167:719.

162 Miskowiak KW, Vinberg M, Harmer CJ, Ehrenreich H, Kessing LV: Erythropoietin: a candidate treatment for mood symptoms and memory dysfunction in depression. Psychopharmacology (Berl) 2012;219:687-698.

163 Chengappa KN, Levine J, Gershon S, Mallinger AG, Hardan A, Vagnucci A, Pollock B, Luther J, Buttenfield J, Verfaille S, Kupfer DJ: Inositol as an add-on treatment for bipolar depression. Bipolar Disord 2000;2:47-55.

164 Levine J, Barak Y, Gonzalves M, Szor H, Elizur A, Kofman O, Belmaker RH: Doubleblind, controlled trial of inositol treatment of depression. Am J Psychiatry 1995;152:792-794.

165 Eden Evins A, Demopulos C, Yovel I, Culhane M, Ogutha J, Grandin LD, Nierenberg AA, Sachs GS: Inositol augmentation of lithium or valproate for bipolar depression. Bipolar Disord 2006;8:168-174.

166 Cattaneo A, Sesta A, Calabrese F, Nielsen G, Riva MA, Gennarelli M: The expression of VGF is reduced in leukocytes of depressed patients and it is restored by effective antidepressant treatment. Neuropsychopharmacology 2010;35:1423-1428.

167 Hunsberger JG, Newton SS, Bennett AH, Duman CH, Russell DS, Salton SR, Duman RS: Antidepressant actions of the exercise-regulated gene VGF. Nat Med 2007;13:1476-1482. 